\title{
A patient- and assessor-blinded randomized controlled trial of axillary reverse mapping (ARM) in patients with early breast cancer
}

Citation for published version (APA):

Beek, M. A., Gobardhan, P. D., Klompenhouwer, E. G., Menke-Pluijmers, M. B., Steenvoorde, P., Merkus, J. W. S., Rutten, H. J. T., Voogd, A. C., \& Luiten, E. J. T. (2020). A patient- and assessor-blinded randomized controlled trial of axillary reverse mapping (ARM) in patients with early breast cancer. European Journal of Surgical Oncology, 46(1), 59-64. https://doi.org/10.1016/j.ejso.2019.08.003

Document status and date:

Published: 01/01/2020

DOI:

10.1016/j.ejso.2019.08.003

Document Version:

Publisher's PDF, also known as Version of record

Document license:

Taverne

Please check the document version of this publication:

- A submitted manuscript is the version of the article upon submission and before peer-review. There can be important differences between the submitted version and the official published version of record.

People interested in the research are advised to contact the author for the final version of the publication, or visit the DOI to the publisher's website.

- The final author version and the galley proof are versions of the publication after peer review.

- The final published version features the final layout of the paper including the volume, issue and page numbers.

Link to publication

\footnotetext{
General rights rights.

- You may freely distribute the URL identifying the publication in the public portal. please follow below link for the End User Agreement:

www.umlib.nl/taverne-license

Take down policy

If you believe that this document breaches copyright please contact us at:

repository@maastrichtuniversity.nl

providing details and we will investigate your claim.
}

Copyright and moral rights for the publications made accessible in the public portal are retained by the authors and/or other copyright owners and it is a condition of accessing publications that users recognise and abide by the legal requirements associated with these

- Users may download and print one copy of any publication from the public portal for the purpose of private study or research.

- You may not further distribute the material or use it for any profit-making activity or commercial gain

If the publication is distributed under the terms of Article $25 \mathrm{fa}$ of the Dutch Copyright Act, indicated by the "Taverne" license above, 


\title{
A patient- and assessor-blinded randomized controlled trial of axillary reverse mapping (ARM) in patients with early breast cancer
}

\author{
Martinus A. Beek ${ }^{\text {a, * }}$, Paul D. Gobardhan ${ }^{\text {a }}$, Elisabeth G. Klompenhouwer ${ }^{\text {b }}$, \\ Marian B. Menke-Pluijmers ${ }^{c}$, Pascal Steenvoorde ${ }^{\mathrm{d}}$, Jos WS. Merkus ${ }^{\mathrm{e}}$, Harm JT. Rutten ${ }^{\text {f, g, }}$ \\ Adri C. Voogd ${ }^{\text {h, i }}$, Ernest JT. Luiten ${ }^{\text {a }}$ \\ a Department of Surgery, Amphia Hospital, Breda, the Netherlands \\ ${ }^{\mathrm{b}}$ Department of Radiology, Netherlands Cancer Institute, Amsterdam, the Netherlands \\ c Department of Surgery, Albert Schweitzer Hospital, Dordrecht, the Netherlands \\ ${ }^{\mathrm{d}}$ Department of Surgery, Medisch Spectrum Twente Hospital, Twente, the Netherlands \\ e Department of Surgery, Haga Hospital, The Hague, the Netherlands \\ ${ }^{\mathrm{f}}$ Department of Surgery, Catharina Hospital, Eindhoven, the Netherlands \\ ${ }^{g}$ Department of Surgery, Maastricht University, Maastricht, the Netherlands \\ h Department of Epidemiology, Faculty of Health Medicine and Life Sciences, Research Institute Growth and Development (GROW), Maastricht University, \\ Maastricht, the Netherlands \\ ${ }^{\mathrm{i}}$ Department of Research, Netherlands Comprehensive Cancer Organisation, Utrecht, the Netherlands
}

\section{A R T I C L E I N F O}

\section{Article history:}

Received 1 July 2019

Received in revised form

1 August 2019

Accepted 4 August 2019

Available online 5 August 2019

\section{Keywords:}

Breast cancer

Axillary lymph node dissection

Lymphedema

Axillary reverse mapping

\begin{abstract}
A B S T R A C T
Background: Axillary lymph node dissection (ALND) in breast cancer patients is infamous for its accompanying morbidity. Selective preservation of upper extremity lymphatic drainage and accompanying lymph nodes crossing the axillary basin - currently resected during a standard ALND - has been proposed as a valuable surgical refinement.

Methods: Peroperative Axillary Reversed Mapping (ARM) was used for selective preservation of upper extremity lymphatic drainage. A multicentre patient- and assessor-blinded randomized study was performed in clinical node negative, sentinel node positive early breast cancer patients. Patients were randomized to undergo either standard-ALND or ARM-ALND. Primary outcome was the presence of surgery-related lymphedema at six, 12 and 24 months post-operatively. Secondary outcomes included patient reported and objective signs and symptoms of lymphedema, pain, paraesthesia, numbness, loss of shoulder mobility, quality of life and axillary recurrence risk.

Results: No significant differences were found between both groups using the water displacement method with respect to measured lymphedema. ARM-ALND resulted in less reported complaints of lymphedema at six, 12 and 24 months postoperatively $(\mathrm{p}<0.05)$. No axillary recurrence was found in both groups.

Conclusions: In contrast to results of volumetric measurement, patient reported outcomes support selective sparing of the upper extremity lymphatic drainage using ARM as valuable surgical refinement in case of ALND in clinically node negative, sentinel node positive early breast cancer. If completion ALND in clinically node negative, sentinel node positive early breast cancer is considered, selective sparing of upper extremity axillary lymphatics by implementing ARM should be carried out in order to reduce morbidity.
\end{abstract}

( $) 2019$ Elsevier Ltd, BASO The Association for Cancer Surgery, and the European Society of Surgical Oncology. All rights reserved.

\footnotetext{
* Corresponding author. Department of Surgery, Amphia Hospital, Molengracht 21, Breda, 4818, CK, the Netherlands.

E-mail address: MBeek@amphia.nl (M.A. Beek).
}

\section{Introduction}

For many decades, axillary lymph node dissection (ALND) has been regarded a valuable technique for final axillary staging and to achieve loco-regional control in breast cancer patients. However, 
ALND is known for its accompanying morbidity, i.e. pain, numbness or paraesthesia, arm and/or shoulder mobility restriction and especially upper extremity lymphedema [1].

Upper extremity lymphedema is reported in up to $77 \%$ of the patients undergoing ALND and is thereby the most frequent complication [2]. Patients with upper extremity lymphedema are more susceptible to upper extremity wound infections, pain, restriction of arm movement, all of which result in structurally lower quality of life [3-6]. Consequently, total health care costs are increased in patients with lymphedema [7].

In 2007, axillary reverse mapping (ARM) was introduced by Nos [8] as an additional surgical refining procedure of ALND. This new technique enables discrimination and preservation of a specific part of upper extremity lymphatic drainage passing through the axillary basin. Preservation of this lymphatic drainage as well as the corresponding lymph nodes is thought to reduce the risk of upper extremity lymphedema.

In 2013, a multicentre patient- and assessor-blinded randomized controlled trial was initiated in The Netherlands (ARM trial). The objective was to determine the clinical utility and safety of selective preservation of upper-limb axillary lymph nodes and lymphatics by means of ARM in sentinel lymph node (SLN) positive patients in whom completion ALND was carried out [9].

\section{Patients and methods}

\section{Study cohort}

In this patient- and assessor-blinded multicentre randomized controlled trial, female patients aged over 18 years presenting with clinically node negative, early invasive breast cancer, scheduled for completion ALND following a positive sentinel node biopsy (SLNB), were included. Exclusion criteria were: an adverse event during the preceding SLNB, a history of breast cancer, axillary surgery or pregnancy. Patients were randomized to undergo either standardALND or ARM-ALND and were blinded for the type of surgery scheduled during the study period. Randomization was performed following completion of the informed consent, using a web-based randomization system, and stratified by hospital. In case of nonidentification and or failure to preserve ARM lymph nodes and/or ARM lymphatics, a standard-ALND was performed. Final analysis was carried out in accordance with the intention to treat principle.

\section{ARM procedure}

The ARM-procedure, i.e. injection of patent blue in the ipsilateral upper extremity, was carried out in both groups. Details of the ARM-procedure have been reported previously [10,11]. In summary, to map the axillary lymph node drainage of the upper extremity, approximately $1.0-2.0 \mathrm{~mL}$ methylene blue dye (Bleu patenté V, Laboratoire Guerbet, Aulnay-sous-Bois, France) was injected subcutaneously in the ipsilateral upper extremity at the medial inter-muscular groove between biceps muscle and triceps muscle. Subsequently, the injection site was massaged gently for $5 \mathrm{~min}$. All procedures were carried out by certified oncologic surgeons familiar with the ARM technique. Following identification, ARM lymphatics and lymph node(s) were either resected (standard-ALND) or preserved (ARM-ALND) according to result of randomization. The intercostobrachial nerve was not routinely spared in both groups.

\section{Settings and locations}

This multicentre randomized controlled trial was conducted in four dedicated breast cancer centres in the Netherlands. In a feasibility study comprising 93 breast cancer patients - preceding this trial - identification of ARM lymphatics was achieved in $94 \%$ by oncologic surgeons familiar with axillary surgery in breast cancer patients [10]. The technique was demonstrated (EL) to breast cancer surgeons participating in the study either on their site or by attending a procedure at our institution.

\section{Blinding}

By study design only the consultant oncologic breast surgeon who performed the ARM-procedure was not blinded since they had to perform either a standard-ALND (including resection of ARM lymph node(s)) or an ARM-ALND (preservation of ARM lymph node(s)). Patients, data managers as well as nurse practitioners (who were responsible for the postoperative data collection and measurements) were all blinded for the procedure performed.

\section{Primary outcome measures}

The determination of lymphedema is generally appreciated by objective volumetric measurement. Therefore, the primary outcome of the trial was the presence of axillary surgery-related lymphedema at six, 12, and 24 months post-operatively, measured by the water displacement method. Measurements were carried out by local nurse practitioners [12]. Lymphedema was defined as a volume increase of the arm at the affected side exceeding $10 \%$, as compared to baseline.

\section{Secondary outcomes}

Secondary endpoints consisted of the patient reported outcomes consisting of: signs of lymphedema in the upper extremity, pain, paraesthesia, numbness, loss of shoulder mobility and the need to wear a compression stocking. Outcomes were scored on a four-point Likert-scale. In the final analyses these four options were dichotomised; the answers 'much' and 'very much' were both combined to one category and the answers 'never' and 'sometimes' on the other hand were both combined to one category.

Additional volumetric circumference measurements at six, 12 and 24 months postoperatively were carried out at four sites: the metacarpophalangeal joints, the wrist, $10 \mathrm{~cm}$ distal from the lateral epicondyle, and $15 \mathrm{~cm}$ proximal of the epicondyle [13]. These were carried out by local nurse practitioners. Lymphedema was defined as an increase of the circumference of $2 \mathrm{~cm}$ or more, as compared to baseline.

Quality of life was measured using the World Health Organisation Quality of Life Assessment (WHOQOL-Bref) questionnaire, validated for breast cancer patients [13].

Shoulder function of the upper limb was measured with the contralateral extremity as reference. A reduction of abduction between both arms of more than $20^{\circ}$ was considered as clinically relevant restriction of shoulder mobility.

The development of axillary recurrence was also defined as a secondary outcome. At each control visit, patients underwent physical examination of the axilla. Additional axillary ultrasonography was only performed in case of clinical suspicion of axillary recurrence.

\section{Ethical approval}

Ethical approval for this study was provided by the medical ethics committee (METC) of Maxima Medisch Centrum, Veldhoven, The Netherlands. Informed consent was obtained from each participant prior to the operation. This study was carried out in compliance with the Helsinki Declaration. The trial is registered in 
the Dutch trial registration (TC 3698).

\section{Data collection}

Pre-operative and postoperative data collection were carried out by local nurse practitioners. Operative data were filled out in an online case report form by the operating surgeon. Data were stored anonymously under a unique trial number. All data were collected in an online case report form and an online participant questionnaire.

\section{Sample size}

The clinical definition of lymphedema is generally accepted as an asymmetrical volume increase exceeding $10 \%$ compared to baseline. The average risk of developing lymphedema following standard ALND in breast cancer patients is $15 \%$ in patients [9]. It was expected that ALND-ARM would reduce the risk to five percent. Based on these assumptions sample size was set at 140 subjects in the ALND-standard and 140 subjects in the ALND-ARM group to be able to reject the null hypothesis that the failure rates for experimental and control subjects are equal with probability (power) 0.8 . The Type I error probability associated with this test of this null hypothesis is 0.05 .

\section{Statistical analysis}

Statistical analyses were performed using SPSS, version 21.0 (SPSS, Inc., Chicago, USA). Chi-square analysis was performed to evaluate proportional differences between the two groups regarding the primary and secondary end-points. T-test was performed to evaluate differences between the two groups regarding some secondary end-points. P values less than 0.05 were considered significant.

\section{Results}

During the course of the study new insights on the value of additional ALND following a positive SLNB rather hampered inclusion $[14,15]$. It was finally decided to stop this study after inclusion of more than 100 patients instead of, the original number of 280 planned patients. Between June 2013 and August 2016, 107 breast cancer patients were randomized in four dedicated breast cancer centres in the Netherlands (Fig. 1). The majority of the patients were included in the Amphia Hospital. Thirteen patients were excluded after the randomization for several reasons: violation of inclusion criteria $(n=4)$, withdrawal of consent $(n=5)$ or refusal by patients on second thoughts based on new clinical findings which considered ALND as an obsolete procedure $(n=4)$

Table 1

Baseline characteristics for 98 breast cancer patients.

\begin{tabular}{|c|c|c|}
\hline Characteristic & $\begin{array}{l}\text { Standard-ALND } \\
\mathrm{N}=46\end{array}$ & $\begin{array}{l}\text { ARM-ALND } \\
\mathrm{N}=48\end{array}$ \\
\hline \multicolumn{3}{|l|}{ Age, years } \\
\hline Mean (Range) & $57.0(42.4-76.6)$ & $58.5(38.8-79.2)$ \\
\hline \multicolumn{3}{|l|}{ Body Mass Index } \\
\hline Mean (Range) & $26.4(19.6-38.3)$ & $26.6(16.2-35.3)$ \\
\hline \multicolumn{3}{|l|}{ Tumor size, $\mathrm{mm}$} \\
\hline Mean (Range) & $22.0(0.0-84.0)$ & $20.3(0.0-91.0)$ \\
\hline \multicolumn{3}{|l|}{ PT stadium (\%) } \\
\hline 0 & $2(4.3)$ & $1(2.1)$ \\
\hline $1 \mathrm{a}$ & $1(2.2)$ & $1(2.1)$ \\
\hline $1 \mathrm{~b}$ & $3(6.5)$ & $6(12.5)$ \\
\hline $1 \mathrm{c}$ & $20(43.5)$ & $17(35.4)$ \\
\hline 2 & $17(37.0)$ & $20(41.7)$ \\
\hline 3 & $3(6.5)$ & $3(6.3)$ \\
\hline \multicolumn{3}{|l|}{ Bloom-Richardson grade (\%) } \\
\hline Well differentiated & $10(21.7)$ & $11(22.9)$ \\
\hline Moderately differentiated & $22(47.8)$ & $23(47.9)$ \\
\hline Poorly differentiated & $10(21.7)$ & $13(27.1)$ \\
\hline Unknown & $4(8.7)$ & $1(2.1)$ \\
\hline Estrogen receptor positive (\%) & $41(89.1)$ & $42(87.5)$ \\
\hline Progesterone receptor positive (\%) & $39(84.5)$ & $38(79.2)$ \\
\hline Her2Neu receptor positive (\%) & $5(10.9)$ & $3(6.3)$ \\
\hline \multicolumn{3}{|c|}{ Total number of sentinel nodes removed } \\
\hline Mean (Range) & $1.87[1-6]$ & $2.04[1-5]$ \\
\hline \multicolumn{3}{|c|}{ Total number of positive sentinel nodes } \\
\hline Mean (Range) & $1.48[1-4]$ & $1.31[1-4]$ \\
\hline Neoadjuvant chemotherapy (\%) & $7(15.2)$ & $8(16.7)$ \\
\hline Adjuvant chemotherapy (\%) & $33(71.7)$ & $34(70.8)$ \\
\hline Adjuvant endocrine treatment (\%) & $41(89.1)$ & $43(89.6)$ \\
\hline Adjuvant trastuzumab (\%) & $5(10.9)$ & $6(12.5)$ \\
\hline Lumpectomy (\%) & $24(52.2)$ & $30(62.5)$ \\
\hline Radiotherapy mamma (\%) & $35(76.1)$ & $37(77.1)$ \\
\hline Radiotherapy supraclavicular (\%) & $7(15.2)$ & $12(25.0)$ \\
\hline
\end{tabular}

ALND: axillary lymph node dissection.

ARM: axillary reverse mapping.

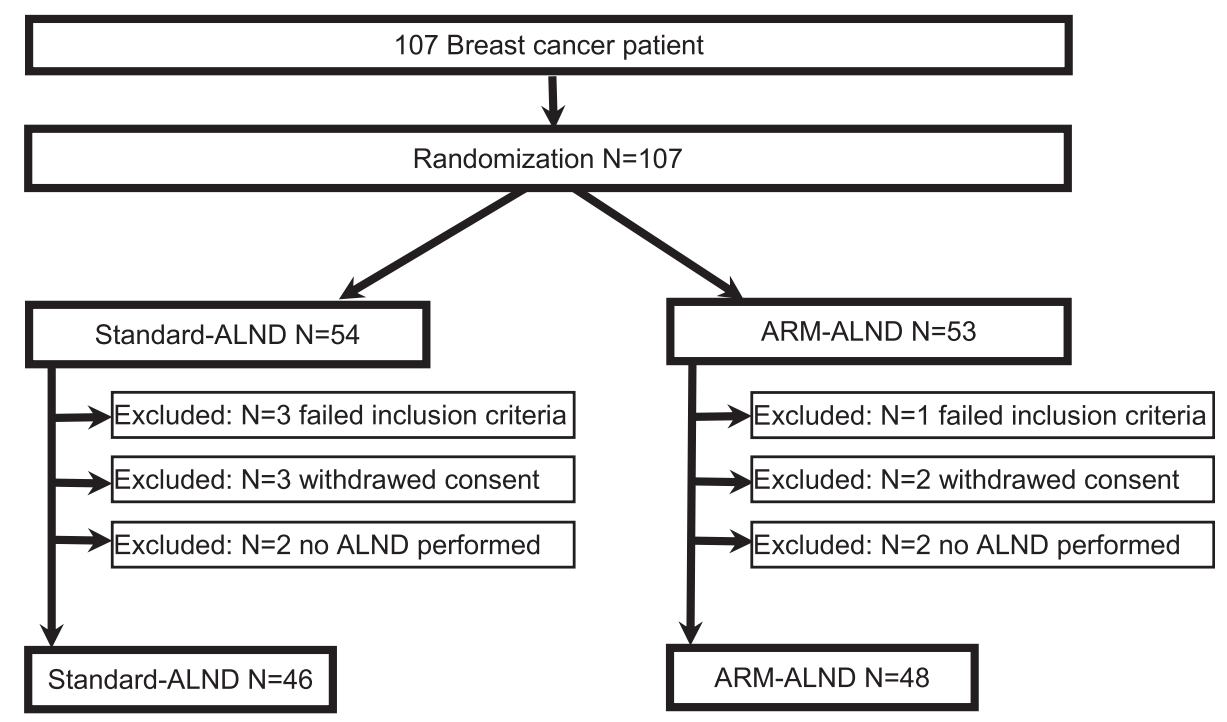

Fig. 1. Flowchart for inclusion and exclusion. 
Table 2

Results of axillary lymph node dissection (ALND) and resection or preservation of axillary ARM lymph nodes.

\begin{tabular}{|c|c|c|}
\hline Characteristic & Standard-ALND & ARM-ALND \\
\hline Patients with identification of ARM lymph nodes (\%) & $35 / 46(76.1)$ & $38 / 48(79.2)$ \\
\hline Patients with preservation of ARM lymph nodes (\%) & $1 / 46(2.2)^{\mathrm{a}}$ & $36 / 48(75.0)^{b}$ \\
\hline Patients with axillary lymph node metastases (\%) & $23 / 46(50.0)$ & $23 / 48(47.9)$ \\
\hline Patients with ARM lymph node metastases (\%) & $1 / 35(2.9)^{\mathrm{a}}$ & $0 / 2(0.0)^{\mathrm{b}}$ \\
\hline $\begin{array}{l}\text { Total number of lymph nodes removed, including ARM nodes } \\
\text { Mean (Range) }\end{array}$ & $14.8(6-34)$ & $13.1(3-27)$ \\
\hline $\begin{array}{l}\text { Total number of ARM lymph nodes removed } \\
\text { Mean (Range) }\end{array}$ & $1.03[1,2]^{\mathrm{a}}$ & $1[1-1]^{b}$ \\
\hline $\begin{array}{l}\text { Total number of positive lymph nodes } \\
\text { Mean (Range) }\end{array}$ & $1.91[1-8]$ & $2.09[1-7]$ \\
\hline
\end{tabular}

Standard-ALND: axillary lymph node dissection including resection of identified ARM lymph nodes.

ARM-ALND: axillary lymph node dissection with preservation of identified ARM lymph nodes.

ARM: axillary reverse mapping.

${ }^{\text {a }}$ In one patient an identified ARM lymph node was not resected (protocol violation Standard-ALND).

b In two patients an identified ARM lymph nodes was not preserved (protocol violation ARM-ALND).

(Fig. 1). Finally, 46 patients were available for analysis in the standard-ALND group and 48 in the ARM-ALND group. Baseline characteristics of both groups are shown in Table 1 . No clinically relevant differences were observed between both groups with respect to these baseline characteristics.

\section{Axillary lymph node status}

The mean number of axillary lymph nodes removed per patient, including the ARM lymph nodes, was 14.8 in the standard-ALND group and 13.1 in the ARM-ALND group (Table 2 ).

Identification of ARM lymphatics and corresponding node was achieved in 35 patients in the standard-ALND group (76.1\%) and in 38 patients in the ARM-ALND group (79.2\%). Preservation of ARM lymphatics and corresponding lymph node was accomplished in 36 out of 38 patients $(94.7 \%)$ in the ARM-ALND group. In contrast to the protocol, in one patient in the standard-ALND group ARM lymphatics and lymph node(s) were not resected.

Axillary lymph node involvement of both groups is shown in Table 2. No difference was found in the number of patients with axillary lymph node metastases: 23 out of 46 patients (50\%) in the standard-ALND group compared to 23 out of 48 patients (47.9\%) in the ARM-ALND group (Table 2). The mean number of involved lymph nodes was comparable between both groups: 1.91 [1-8] in the standard-ALND group versus 2.09 [1-7] in the ARM-ALND group.

An ARM-node metastasis was found in one out of 35 patients in the standard-ALND group. In two patients in the ARM-ALND group in whom ARM lymph nodes could accidentally not be preserved, i.e protocol violation, no metastases were found.

\section{Upper extremity lymphedema by volumetric measurement}

At six, 12 and 24 months, no statistically significant differences were observed in the percentage of patients developing

Table 3

Primary end-point, upper extremity lymphedema using the water displacement method $^{\mathrm{b}}$.

\begin{tabular}{llll}
\hline $\begin{array}{l}\text { Characteristic } \\
10 \% \text { volume increase }\end{array}$ & Standard-ALND & ARM-ALND & $p$ \\
\hline 6 months (\%) & $9 / 42(21.4)$ & $11 / 44(25.0)$ & $0.191^{\mathrm{a}}$ \\
12 months (\%) & $9 / 39(23.4)$ & $4 / 44(9.1)$ & $0.080^{\mathrm{a}}$ \\
24 months (\%) & $10 / 31(32.3)$ & $8 / 35(23.5)$ & $0.432^{\mathrm{a}}$ \\
\hline
\end{tabular}

ALND: axillary lymph node dissection.

ARM: axillary reverse mapping.

a Chi-Square Tests.

b Lymphedema was defined as a $10 \%$ increase in volume relative to baseline. lymphedema according to volumetric measurement using the water displacement method (Table 3). After a follow up of 24 months lymphedema was found in 10 out of 31 patients $(32.3 \%)$ in the standard-ALND group as compared to eight of 35 patients (23.5\%) in the ARM-ALND group ( $\mathrm{p}=0.432)$. Arm circumference measurements at four sites (the metacarpophalangeal joints, the wrist, distal from the lateral epicondyle and proximal of the epicondyle) after six, 12 and 24 months showed no significant difference between both groups. Given the limitation of too few data points from early termination we analysed also an even a lower threshold of only five percent post study. However even when using five percent as a cut-off level for defining lymphedema, which resulted in a substantial increase in the proportion of patients with lymphedema, again no statistically significant differences were observed between patients in the standard-ALND and the ARM-ALND group (Supplement Table).

\section{Upper extremity lymphedema by patient reported outcomes}

In contrast to the standard-ALND group, patients in the ARMALND group reported significantly less swelling of the upper extremity (Table 4); after two years "much" or "very much" complaints of lymphedema were reported by eight of 30 patients (26.7\%) in the standard-ALND group in contrast to two of the 32 patients $(6.1 \%)$ in the ARM-ALND group $(\mathrm{p}=0.025)$.

Table 4

Patient reported outcomes.

\begin{tabular}{llll}
\hline Characteristic & Standard-ALND (\%) & ARM-ALND (\%) & $p$ \\
\hline \multicolumn{2}{c}{ Do you have swelling or lymphedema? } & & \\
6 months (much/very much) & $5 / 44(5.7)$ & $0 / 43(0)$ & $0.023^{\mathrm{a}}$ \\
12 months (much/very much) & $8 / 41(19.5)$ & $2 / 40(5.0)$ & $0.047^{\mathrm{a}}$ \\
24 months (much/very much) & $8 / 30(26.7)$ & $2 / 33(6.1)$ & $0.025^{\mathrm{a}}$ \\
Do you have pain in your arm or shoulder? & & \\
6 months (much/very much) & $13 / 44(29.5)$ & $6 / 43(11.6)$ & $0.039^{\mathrm{a}}$ \\
12 months (much/very much) & $9 / 41(22.0)$ & $6 / 40(15.0)$ & $0.421^{\mathrm{a}}$ \\
24 months (much/very much) & $8 / 30(25.8)$ & $3 / 33(9.1)$ & $0.076^{\mathrm{a}}$ \\
Do you wear a compressive arm sleeve? & & \\
6 months & $4 / 44(9.1)$ & $0 / 43(0)$ & $0.043^{\mathrm{a}}$ \\
12 months & $6 / 41(14.6)$ & $1 / 40(2.5)$ & $0.052^{\mathrm{a}}$ \\
24 months & $5 / 30(16.7)$ & $1 / 33(3.0)$ & $0.066^{\mathrm{a}}$ \\
Vas score & & \\
6 months (mean) & $3.09(\mathrm{~N}=44)$ & $2.12(\mathrm{~N}=43)$ & $0.055^{\mathrm{b}}$ \\
12 months (mean) & $2.54(\mathrm{~N}=41)$ & $1.63(\mathrm{~N}=40)$ & $0.044^{\mathrm{b}}$ \\
24 months (mean) & $2.33(\mathrm{~N}=30)$ & $2.06(\mathrm{~N}=33)$ & $0.611^{\mathrm{b}}$ \\
\hline
\end{tabular}

ALND: axillary lymph node dissection.

ARM: axillary reverse mapping.

a Chi-Square Tests.

b T-test. 
"Much" or "very much" pain in the upper extremity and or shoulder was reported more frequently in patients treated with a standard-ALND as compared to ARM-ALND. This numerical difference only reached statistical significance at six months postoperatively (29.5\% versus $11.6 \%, p=0.039$, Table 4 ).

Patients in whom ARM-ALND had been performed less frequently needed to wear a compressive arm sleeve which reached statistical difference only at six and 12 months postoperatively. At two years follow up one out of 33 patients in the ARM-ALND group wore a compressive sleeve in contrast to five of 30 in the standardALND group ( $3 \%$ versus $16.7 \%$; $p=0.066$, Table 4 ).

\section{Shoulder mobility}

No significant differences were found concerning the range of shoulder movements at six, 12 and 24 months between both groups both by objective measurement as well as by patient reported outcomes. At 24 months postoperatively, 91\% of the patients (30/ 33 ) in the ARM-ALND group reported no movement restriction versus $90 \%$ in the standard-ALND group (27/30).

\section{Quality of life}

The quality of life measured using WHOQOL-Bref questionnaires validated for breast cancer patients was not significant different between both groups on all four domains. At 24 months the mean score on the algBRT0 was 3,85 in the standard-ALND group versus 3,79 in the ARM-ALND group ( $\mathrm{p}=0.969$ ), the mean of the algBRT1 was 3,42 in the standard-ALND group versus 3,71 in the ARM-ALND group $(\mathrm{p}=0.056)$, the mean of the $\operatorname{algBRT2}$ was 3,63 in the standard-ALND group versus 3,89 in the ARM-ALND group $(\mathrm{p}=0.138)$, the mean of the $\operatorname{algBRT3}$ was 3,74 in the standard-ALND group versus 3,89 in the ARM-ALND group $(\mathrm{p}=0.376)$.

\section{Locoregional recurrence rate}

None of the patients developed a loco-regional recurrence during a median follow up period of 24 months.

\section{Discussion}

To our knowledge this is the first patient- and assessor-blinded randomized multicentre study reporting results of the clinical value of adding ARM to a standard ALND with subsequent preservation of upper extremity lymphatics and corresponding lymph node(s) in the axillary basin.

This study demonstrates that patients report less swelling of their upper extremity or complaints which they relate to development of lymphedema. However, these self-reported differences are not supported by objective volumetric measurements which are currently wide accepted as the gold standard for defining the presence of lymphedema. Apparently, patients do experience lymphedema-like complaints in the absence of measurable increase of arm volume. The aforementioned increase of arm volume has always been held as the major responsible cause for axillary surgery induced morbidity. The value of PROMs however is gaining interest over the recent decades and may better reflect the true impact of introduction of surgical refinements aiming to reduce morbidity as compared to current objective data. Despite the fact that cut-off levels to define lymphedema are evidence based, the results of this study implicate that ALND-induced morbidity may be more complex than the sole definition of volume increase, which has also been recognised by others [14]. The validity of the results of this randomized multicentre study is strengthened by the fact that both patients as well as nurse practitioners were blinded for the type of axillary surgery performed. Clinical signs of lymphedema were found in $26 \%$ of patients treated with standard-ALND which is comparable to results reported in literature [14]. Two years after surgery only six percent of patients in whom upper extremity lymphatics and lymph nodes were preserved during ALND by means of ARM reported complaints of lymphedema. A large randomized controlled trial on the clinical value of axillary radiotherapy versus standard ALND reported that after 10 years follow up $14.6 \%$ of patients in the radiotherapy group had signs of lymphedema vs $29.4 \%$ in the standard ALND group [14].

Differences in the proportion of patients with regard to shoulder pain and necessity to wear a compressive arm sleeve did not reach statistical significance at all time-points, which may be due to the relatively small study size.

The technique of ARM - achieving almost 95\% preservation lymphatics and corresponding lymph node(s) in the axillary basin while performing an ALND in this multicentre study - reflects the feasibility of the procedure and should be easy to carry out by surgeons familiar with axillary surgery. Deviation of parts of upper extremity lymphatics crossing the axillary basin does not occur in every patient and is reflected by the absence of ARM lymph nodes and lymphatics in $20-25 \%$ in both groups of patients. The former has also been found by others [16].

A major limitation of our study is the fact that we had to stop our inclusion prematurely. Shortly after the start of our trial in 2013, the results of the American College of Surgeons Oncology Group (ACOSOG) Z0011 trial showed that omitting completion ALND did not result in inferior overall- and disease free survival in CT1-2N0 breast cancer patients with one to three sentinel lymph node(s) treated with breast-conserving therapy [15]. Subsequently due to results of the European Organisation for Research and Treatment of Cancer (EORTC) AMAROS trial, published in 2014, replacement of ALND by axillary radiotherapy was widely accepted based on significant reduction of morbidity without compromising oncologic safety [14]. The new insights arising from the ACOSOG Z0011trail and the AMAROS trial hampered the inclusion and finally left us to decide to stop inclusion almost half way. This resulted in the fact that we were not able to reach statistical power.

Another limitation is the fact the some results were missing. After six, 12 and 24 months, respectively seven, six and 18 included patients were lost to follow up, this was equal for both groups. The most common reasons for loss of follow up were; no-show at follow up without a specified motive, moving away or death.

Completion ALND, in breast cancer patients with a positive sentinel lymph node, can still be regarded as a valid alternative in case of contraindication for axillary radiotherapy, i.e. following direct breast reconstruction, patient preference or in regions of the world where accessibility to radiotherapy facilities is limited [17]. Furthermore, in patients with primary clinically node positive disease, ALND is generally still regarded as first choice of axillary treatment. Given the fact that use of neoadjuvant chemotherapy in these cases will result in up to $40 \%$ complete axillary remission, different less invasive surgical staging procedures are currently subject of several studies thereby further reducing the role of axillary surgical clearance [18-21]. In case of radiological complete axillary remission following neoadjuvant chemotherapy, application of ARM and selective sparing of upper extremity lymphatics during ALND has been reported to be oncologically safe [22].

During the two year follow up none of the patients developed an axillary nodal recurrence. In only one of the 35 patients $(2.9 \%)$ the removed ARM lymph node contained a macrometastasis which compares favourably to the false negative rate of the SLNB [23].

Up until now, Yue et al. reported results of the only prospective randomized study in which preserving the lymphatic drainage system of the upper limb by means of the ARM technique 
significantly reduced postoperative morbidity [24]. In this single surgeon study, 265 patients were included with an average followup period of 20 months. Upper extremity lymphedema measured by the circumference measurement method, occurred in 42 patients (33\%) in the control group in contrast to seven patients (6\%) in the ARM group $(\mathrm{p}<0.001)$. In contrast to our study, patients and researchers in this study were not blinded for the procedure being carried out and patients treated with neo-adjuvant chemotherapy or breast-conservation surgery were excluded.

In summary, the addition of selective preservation of upperlimb axillary lymph nodes and lymphatic drainage by means ARM during ALND reduces the incidence of patients reported upper extremity lymphedema without compromising oncological safety as compared to standard-ALND thereby reducing morbidity.

\section{Conflict of interest statement}

The authors declare there is no conflict of interest.

\section{Funding}

This work was supported financially by grants from Pink Ribbon foundation (currently KWF) and the Maurits and Anna the Kock foundation.

\section{Acknowledgements}

The authors acknowledge the patients, their relatives and treating clinicians, and the hospitals who agreed to participate in this study. They also acknowledge S. den Besten (nurse practitioner of Albert Schweitzer hospital, Dordrecht, The Netherlands), M. Bouwman (nurse practitioner of Haga hospital, The Hague, The Netherlands), J. Hover (nurse practitioner of Amphia Hospital, Breda, The Netherlands), D.C.H. van der Meer (nurse practitioner of Amphia Hospital, Breda, The Netherlands), C. Ramlal (nurse practitioner of Albert Schweitzer hospital, Dordrecht, The Netherlands), H. Rikkers (nurse practitioner of Albert Schweitzer hospital, Dordrecht, The Netherlands), A. Stam (clinical research coordinator of Medisch Spectrum Twente hospital, Twente, The Netherlands) and J.J.A. Woolschot (nurse practitioner of Amphia Hospital, Breda, The Netherlands).

\section{Appendix A. Supplementary data}

Supplementary data to this article can be found online at https://doi.org/10.1016/j.ejso.2019.08.003.

\section{References}

[1] Hack TF, Cohen L, Katz J, Robson LS, Goss P. Physical and psychological morbidity after axillary lymph node dissection for breast cancer. J Clin Oncol : Off J Am Soc Clin Oncol 1999 Jan;17(1):143-9. PubMed PMID: 10458227.

[2] Schijven MP, Vingerhoets AJ, Rutten HJ, Nieuwenhuijzen GA, Roumen RM, van Bussel ME, et al. Comparison of morbidity between axillary lymph node dissection and sentinel node biopsy. Eur J Surg Oncol : J Eur Soc Surg Oncol Br Assoc Surg Oncol 2003 May;29(4):341-50. PubMed PMID: 12711287.

[3] Cormier JN, Askew RL, Mungovan KS, Xing Y, Ross MI, Armer JM. Lymphedema beyond breast cancer: a systematic review and meta-analysis of cancerrelated secondary lymphedema. Cancer 2010 Nov 15;116(22):5138-49. PubMed PMID: 20665892

[4] McWayne J, Heiney SP. Psychologic and social sequelae of secondary lymphedema: a review. Cancer 2005 Aug 1;104(3):457-66. PubMed PMID: 15968692.

[5] Park JE, Jang HJ, Seo KS. Quality of life, upper extremity function and the effect of lymphedema treatment in breast cancer related lymphedema patients. Ann Rehabil Med 2012 Apr;36(2):240-7. PubMed PMID: 22639749. Pubmed Central PMCID: 3358681.

[6] Voogd AC, Ververs JM, Vingerhoets AJ, Roumen RM, Coebergh JW, Crommelin MA. Lymphoedema and reduced shoulder function as indicators of quality of life after axillary lymph node dissection for invasive breast cancer.
Br J Surg 2003 Jan;90(1):76-81. PubMed PMID: 12520579.

[7] Shih YC, Xu Y, Cormier JN, Giordano S, Ridner SH, Buchholz TA, et al. Incidence, treatment costs, and complications of lymphedema after breast cancer among women of working age: a 2-year follow-up study. J Clin Oncol : Off J Am Soc Clin Oncol 2009 Apr 20;27(12):2007-14. PubMed PMID: 19289624.

[8] Nos C, Lesieur B, Clough KB, Lecuru F. Blue dye injection in the arm in order to conserve the lymphatic drainage of the arm in breast cancer patients requiring an axillary dissection. Ann Surg Oncol 2007 Sep;14(9):2490-6. PubMed PMID: 17549570.

[9] Klompenhouwer EG, Gobardhan PD, Beek MA, Voogd AC, Luiten EJ. The clinical relevance of axillary reverse mapping (ARM): study protocol for a randomized controlled trial. Trials 2013;14:111. PubMed PMID: 23782712. Pubmed Central PMCID: 3663653.

[10] Gobardhan PD, Wijsman JH, van Dalen T, Klompenhouwer EG, van der Schelling GP, Los J, et al. ARM: axillary reverse mapping - the need for selection of patients. Eur J Surg Oncol : J Eur Soc Surg Oncol Br Assoc Surg Oncol 2012 Aug:38(8):657-61. PubMed PMID: 22607749.

[11] Beek MA, Gobardhan PD, Klompenhouwer EG, Rutten HJ, Voogd AC, Luiten EJ Axillary reverse mapping (ARM) in clinically node positive breast cancer patients. Eur J Surg Oncol : J Eur Soc Surg Oncol Br Assoc Surg Oncol 2015 Jan;41(1):59-63. PubMed PMID: 25468747.

[12] Beek MA, Te Slaa A, van der Laan L, Mulder PG, Rutten HJ, Voogd AC, et al Reliability of the inverse water volumetry method to measure the volume of the upper limb. Lymphatic Res Biol 2015 Jun;13(2):126-30. PubMed PMID: 26091408.

[13] Development of the world health organization WHOQOL-BREF quality of life assessment. The WHOQOL group. Psychol Med 1998 May;28(3):551-8. PubMed PMID: 9626712.

[14] Donker M, van Tienhoven G, Straver ME, Meijnen P, van de Velde CJ, Mansel RE et al. Radiotherapy or surgery of the axilla after a positive sentinel node in breast cancer (EORTC 10981-22023 AMAROS): a randomised, multicentre, open-label, phase 3 non-inferiority trial. Lancet Oncol 2014 Nov;15(12): 1303-10. PubMed PMID: 25439688. Pubmed Central PMCID: 4291166.

[15] Giuliano AE, Hunt KK, Ballman KV, Beitsch PD, Whitworth PW, Blumencranz PW, et al. Axillary dissection vs no axillary dissection in women with invasive breast cancer and sentinel node metastasis: a randomized clinical trial. JAMA: J Am Med Assoc 2011 Feb 9;305(6):569-75. PubMed PMID: 21304082

[16] Beek MA, Gobardhan PD, Schoenmaeckers EJ, Klompenhouwer EG, Rutten HJ Voogd AC, et al. Axillary reverse mapping in axillary surgery for breast cancer: an update of the current status. Breast cancer research and treatment 2016 Aug;158(3):421-32. PubMed PMID: 27444925.

[17] Luiten EJ, Beek MA, Rubio IT. Clinical utility of Axillary Reverse Mapping (ARM) in an era of changing perceptions concerning axillary surgery. Eur J Surg Oncol : J Eur Soc Surg Oncol Br Assoc Surg Oncol 2016 Feb 10. http://dx. doi.org/10.1016/j.ejso.2016.01.022. PubMed PMID: 26898840, 0748-7983/ 2016 Published by Elsevier Ltd.

[18] Donker M, Straver ME, Wesseling J, Loo CE, Schot M, Drukker CA, et al. Marking axillary lymph nodes with radioactive iodine seeds for axillary staging after neoadjuvant systemic treatment in breast cancer patients: the MARI procedure. Ann Surg 2015 Feb;261(2):378-82. PubMed PMID: 24743607.

[19] van Nijnatten TJA, Simons JM, Smidt ML, van der Pol CC, van Diest PJ, Jager A, et al. A novel less-invasive approach for axillary staging after neoadjuvant chemotherapy in patients with axillary node-positive breast cancer by combining radioactive iodine seed localization in the axilla with the sentine node procedure (RISAS): a Dutch prospective multicenter validation study. Clin Breast Canc 2017 Aug:17(5):399-402. PubMed PMID: 28487053.

[20] Siso C, de Torres J, Esgueva-Colmenarejo A, Espinosa-Bravo M, Rus N, Cordoba $\mathrm{O}$, et al. Intraoperative ultrasound-guided excision of axillary clip in patients with node-positive breast cancer treated with neoadjuvant therapy (ILINA trial) : a new tool to guide the excision of the clipped node after neoadjuvant treatment. Ann Surg Oncol 2018 Mar;25(3):784-91. PubMed PMID: 29197044.

21] Caudle AS, Yang WT, Krishnamurthy S, Mittendorf EA, Black DM, Gilcrease MZ et al. Improved axillary evaluation following neoadjuvant therapy for patients with node-positive breast cancer using selective evaluation of clipped nodes: implementation of targeted axillary dissection. J Clin Oncol : Off J Am Soc Clin Oncol 2016 Apr 1;34(10):1072-8. PubMed PMID: 26811528. Pubmed Central PMCID: 4933133.

[22] Beek MA, Tetteroo E, Luiten EJ, Gobardhan PD, Rutten HJ, Heijns JB, et al Clinical impact of breast MRI with regard to axillary reverse mapping in clinically node positive breast cancer patients following neo-adjuvant chemotherapy. Eur J Surg Oncol : J Eur Soc Surg Oncol Br Assoc Surg Oncol 2016 May;42(5):672-8. PubMed PMID: 26898838.

[23] Krag DN, Anderson SJ, Julian TB, Brown AM, Harlow SP, Ashikaga T, et al. Technical outcomes of sentinel-lymph-node resection and conventional axillary-lymph-node dissection in patients with clinically node-negative breast cancer: results from the NSABP B-32 randomised phase III trial. Lancet Oncol 2007 Oct;8(10):881-8. PubMed PMID: 17851130.

[24] Yue T, Zhuang D, Zhou P, Zheng L, Fan Z, Zhu J, et al. A prospective study to assess the feasibility of axillary reverse mapping and evaluate its effect on preventing lymphedema in breast cancer patients. Clin Breast Canc 2015 Feb 19. PubMed PMID: 25776198, Submitted: Nov 25, 2014; Revised: Jan 22, 2015; Accepted: Jan 31, 2015. 